\title{
Effect of Fintech on the Productivity in the Taiwan Banking Industry
}

\author{
Yung-Lieh Yang1, Hsiu-Wen Hsueh², Ming-Hsiang Huang ${ }^{2}$, Tsui-Yueh Cho $^{3 *}$, Yausuyuki Kishi ${ }^{4}$ \\ ${ }^{1}$ Ling Tung University No.1, Ling tung Rd., Taichung City, Taiwan. \\ 2 National Changhua University of Education No.2, Shi-Da Road, Changhua City, Taiwan. \\ ${ }^{3}$ National Taichung University of Science and Technology No.129, Sec. 3, Sanmin Rd., Taichung City, Taiwan. \\ ${ }^{4}$ Niigata University 8050 Ikarashi 2 Nocho, Nishi Ward, Niigata, Niigata Prefecture, Japan. \\ * Corresponding author. Tel.: 04-22196063; email: yueh@nutc.edu.tw \\ Manuscript submitted March 27, 2017; accepted July 26, 2017. \\ doi: 10.17706/ijeeee.2017.7.4.255-263
}

\begin{abstract}
The development of financial technology has fostered a wave revolutionary change in financial service industry worldwide. The objective of this study is to examine whether the adoption of Fintech contributes to the productivity growth of the Taiwan banking industry in 2015 . To investigate such potential effect, the study use the preferred Cost Malmquist Index to estimate the 25 listed sample banks over the period from 2010 to 2015. The empirical result suggests the observed period 2014-2015, the $\Delta \mathrm{PTE}, \Delta \mathrm{AE}$, $\Delta \mathrm{PE}$, and $\Delta \mathrm{CSE}$ are improving by $0.01 \%, 0.13 \%, 0.42 \%$, and $0.10 \%$ respectively. Moreover, the degree of $\Delta \mathrm{T}$ deterioration is much improved relative to the other observe periods without adoption of Fintech. It provides the positive evidence to support an adoption of Fintech contribute a potential growth of competiveness of the Taiwan banking industry.
\end{abstract}

Key words: Cost Malmquist productivity index, bank productivity, fintech.

\section{Introduction}

The theory of modern financial intermediation suggests that the security, privacy, trust and information asymmetry are the niches of the existence of financial intermediaries. Nevertheless, the traditional financial intermediary requires many layers to obtain such quality. In the aftermath of the 2008 U. S. financial crisis, consumers has casted a doubt on the efficiency of the traditional financial intermediary. Driven by this force and the advances of technology, several savvy start-ups using financial technology has foster a wave of Fintech revolutionary which is actually taking out the market share and changing the landscape of financial incumbent. These destructive innovations spans in four aspects, infrastructure, money and payment, market, and marketplace, for example, Bitcoin, robot advisor, and P-to-P lending. Overall, those innovations of Fintech have provided more convenient, secure, and efficient services to the consumers. Thus, the effectiveness of disruptive innovation actually resides on the removing of the layers of intermediaries which have long embedded in the traditional financial services. The global Fintech development activity is relative slow from 2008 to 2011 but become explosive in 2015. The Fintech has spreading from the U.S.A., Europe, and the Asia since 2015.

To ensure the soundness of financial system and sustainable growth of the financial institutions in the revolutionary Fintech era, Taiwan Financial Supervisory Commission (TFSC) has declared 2015 as the first year of Fintech in Taiwan and announced a series of policies to promote the development and applications 
of Fintech in its financial industry. On May 12, 2016, TFSC further announced the Fintech Development Strategy White Paper which discloses its vision and policy directions regarding the revolutionary Fintech Innovation, and its proposed landscape of Taiwan Fintech society in 2020. TFSC has allowed financial institutions to own 100\% share of the Fintech firms. To secure their landscape and sustainable growth, several major Taiwan domestic banks have fostered a wave of innovation to cope with the hyper competition from new Fintech start-ups. A sound cost efficiency and productivity is very important to the sustainable growth of Taiwanese financial institutions. Thus, an evaluation of the effect of adoption Fintech on the productivity of banking industry has become an important issue. The objective of this study is to examine the effect of Fintech development on the productivity in the Taiwan banking industry.

The remainder of this paper is organized as follows. Section 2 presents a review of the relevant literature. Section 3 provides a discussion of the methodology used in the study, which is followed by an evaluation of the results on Section 4. The paper concludes with a summary analysis of the findings in Section 5.

\section{Review of Literature}

Recently, the Cost Malmquist productivity Index (CM) approach has been evolved as a preferred approach to estimate productivity change [1]-[3], (Maniadakis and Thanassoulis, 2004:Yang and Huang, 2009: Yang, Huang and Sheng, 2010). The origination of the CM approach can be traced to the master piece of Maniadakis et al. (2004). Before the work of Maniadakis et al. (2004), the research of productivity namely used the traditional production-based Malmquist indexes which failed to capture one of the most important aspects of managements, the allocative efficiency. Maniadakis et al. (2004) [1] suggested that the impact of allocative efficiency change on productivity change should be accounted for in the model. Since then the CM has become a preferred approach in the estimation of productivity.

Previous literature has well documented that the variable returns to scale (VRS) is more flexible and envelops the data in a tighter way than the constant returns to scale (CRS) under DEA approach (Yang et al., 2009) [2]. Departing from the work of Maniadakis et al. (2004), Yang et al. (2009) relief the assumption of CRS and proposed an alternative CM based on the VRS to estimate productivity change. Their empirical result further provide evidence to support that the $\mathrm{CM}$ approach outperform the traditional approach in the sense that the alternative approach convey inside cost information which carry important managerial implication.

\section{Methodology}

Assume that at time period $\mathrm{t}$ a decision making unit (DMU) or a Taiwan's bank uses $\mathrm{N}$ inputs $\left(\mathrm{x}^{\mathrm{t}}\right)$ to produce $M$ outputs $\left(\mathrm{y}^{\mathrm{t}}\right)$. The production technology at time $t$ defines the input requirement set as: $L^{t}\left(y^{t}\right)=\left\{x^{t}: x^{t}\right.$ can produce $\left.\mathrm{y}^{\mathrm{t}}\right\} . \quad$ The input distance function [4]-[6] (Shepherd 1970; Färe 1988; Färe et al. 1994) is defined at time t as: $D_{I}^{t}\left(y^{t}, x^{t}\right)=\sup _{\rho}\left\{\rho:\left(x^{t} / \rho\right) \in L^{t}\left(y^{t}\right), \rho>0\right\}$. The input distance function is the reciprocal of the Farrell's (1957) [7] input-oriented measure of efficiency and so $D_{I}^{t}\left(y^{t}, x^{t}\right)$ can be used to measure production technical efficiency at time period t, i.e.,

$$
T E_{I}^{t}\left(y^{t}, x^{t}\right)=\frac{1}{D_{I}^{t}\left(y^{t}, x^{t}\right)} \leq 1
$$

A similarly defined distance function, denoted by $D_{I}^{t+1}\left(y^{t+1}, x^{t+1}\right)$, can be used to measure efficiency in time period $\mathrm{t}+1$, i.e. $T E_{I}^{t+1}\left(y^{t+1}, x^{t+1}\right)=1 / D_{I}^{t+1}\left(y^{t+1}, x^{t+1}\right)$. In order to assess change in productivity over 
time or the Malmquist index, two mixed-period input distance functions need to be defined as : $D_{I}^{t}\left(y^{t+1}, x^{t+1}\right)=\sup _{\rho}\left\{\rho:\left(x^{t+1} / \rho\right) \in L^{t}\left(y^{t+1}\right), \rho>0\right\}$ and $D_{I}^{t+1}\left(y^{t}, x^{t}\right)=\sup _{\rho}\left\{\rho:\left(x^{t} / \rho\right) \in L^{t+1}\left(y^{t}\right), \rho>0\right\}$.

When input prices, $w^{t} \in R_{+}^{N}$, are available, one may define the production technology in terms of cost function, which is

$$
C^{t}\left(y^{t}, w^{t}\right)=\min _{x}\left\{w^{t} x: x \in L^{t}\left(y^{t}\right), w^{t}>0\right\}
$$

The cost function, $C^{t}\left(y^{t}, w^{t}\right)$, which is dual to the input requirement set $L^{t}\left(y^{t}\right)$ of production, is the minimum cost of producing a given output $y^{t}$ with the input prices at $w^{t}$ under the th period technology. Corresponding to the input distance function or the input-oriented technical efficiency, the $t$ th period cost efficiency $\left(C E^{t}\right)$ is defined as

$$
C E^{t}\left(y^{t}, x^{t}, w^{t}\right)=\frac{C^{t}\left(y^{t}, w^{t}\right)}{w^{t} x^{t}} \leq 1
$$

Had the outputs yt were produced under the $(t+1)$ production technology and input prices at wt+1, the cost function would be $C^{t+1}\left(y^{t}, w^{t+1}\right)=\min _{x}\left\{w^{t+1} x: x \in L^{t+1}\left(y^{t}\right), w^{t+1}>0\right\}$. Similarly, $C^{t}\left(y^{t+1}, w^{t}\right)=\min _{x}\left\{w^{t} x: x \in L^{t}\left(y^{t+1}\right), w^{t}>0\right\}$. Thus, $C^{t+1}\left(y^{t}, w^{t+1}\right)$ and $C^{t}\left(y^{t+1}, w^{t}\right)$ are the mixed-period minimum cost functions. The corresponding mixed-period cost efficiencies are $C E^{t+1}\left(y^{t}, x^{t}, w^{t+1}\right)=\frac{C^{t+1}\left(y^{t}, w^{t+1}\right)}{w^{t+1} x^{t}}$ and $C E^{t}\left(y^{t+1}, x^{t+1}, w^{t}\right)=\frac{C^{t}\left(y^{t+1}, w^{t}\right)}{w^{t} x^{t+1}}$. Dual to the measure of the production Malmquist productivity index, the Cost Malmquist productivity index is defined as the geometric mean of the two ratios of cost efficiency,

$$
\begin{gathered}
C M=\left[\frac{C E^{t}\left(y^{t}, x^{t}, w^{t}\right)}{C E^{t}\left(y^{t+1}, x^{t+1}, w^{t}\right)} \times \frac{C E^{t+1}\left(y^{t}, x^{t}, w^{t+1}\right)}{C E^{t+1}\left(y^{t+1}, x^{t+1}, w^{t+1}\right)}\right]^{\frac{1}{2}} \\
=\left[\frac{w^{t} x^{t+1} / C^{t}\left(y^{t+1}, w^{t}\right)}{w^{t} x^{t} / C^{t}\left(y^{t}, w^{t}\right)} \times \frac{w^{t+1} x^{t+1} / C^{t+1}\left(y^{t+1}, w^{t+1}\right)}{w^{t+1} x^{t} / C^{t+1}\left(y^{t}, w^{t+1}\right)}\right]^{\frac{1}{2}}
\end{gathered}
$$

The Cost Malmquist productivity index (4) measures the change over time in cost efficiency. Parallel to the decomposition of production Malmquist productivity index, the CM may be decomposed into the effects due to the improvement in production technology, in production efficiency, due to variation in input prices and production scale. Recently, Maniadakis et al. (2004) have proposed a decomposition of CM under the assumption of constant returns to scale technology. However, since the evidence shown that the sample banks operation in Taiwan is more likely subject to variable returns to scale, we further extend the decomposition of the Cost Malmquist productivity index under the variable returns to scale.

It can be shown that the Cost Malmquist productivity index CM can be decomposed as follows:

$$
C M=\Delta P T E \times \Delta T \times \triangle A E \times \Delta P E \times \Delta C S E
$$


where the first component $\triangle \mathrm{PTE}$ is the pure technical efficiency change and the second component $\Delta \mathrm{T}$ is the technical change can be defined as follow:

$$
\begin{gathered}
\Delta P T E=\frac{D_{I V}^{t+1}\left(y^{t+1}, x^{t+1}\right)}{D_{I V}^{t}\left(y^{t}, x^{t}\right)}=\frac{T E_{I V}^{t}\left(y^{t}, x^{t}\right)}{T E_{I V}^{t+1}\left(y^{t+1}, x^{t+1}\right)} \\
\Delta T=\left[\frac{D_{I V}^{t}\left(y^{t+1}, x^{t+1}\right)}{D_{I V}^{t+1}\left(y^{t+1}, x^{t+1}\right)} \times \frac{D_{I V}^{t}\left(y^{t}, x^{t}\right)}{D_{I V}^{t+1}\left(y^{t}, x^{t}\right)}\right]^{\frac{1}{2}}
\end{gathered}
$$

The third component $\triangle \mathrm{AE}$ is the allocative efficiency change defined as

$$
A E=\frac{C_{I V}^{t}\left(y^{t}, w^{t}\right) \times D_{I V}^{t}\left(y^{t}, w^{t}\right) / w^{t} x^{t}}{C_{I V}^{t+1}\left(y^{t+1}, w^{t+1}\right) \times D_{I V}^{t+1}\left(y^{t+1}, w^{t+1}\right) / w^{t+1} x^{t+1}}
$$

The subscript "V" under the cost function indicates the measure of production cost under variable returns to scale technology. The numerator, as shown by Maniadakis et al. (2004) and denoted as $A E\left(y^{t}, x^{t}, w^{t}\right)=C_{I V}^{t}\left(y^{t}, w^{t}\right) \times D_{I V}^{t}\left(y^{t}, w^{t}\right) / w^{t} x^{t}$, is the input-oriented measure of allocative efficiency at time period t. The $\triangle \mathrm{AE}$ represents the change over time the allocative efficiency, $\triangle A E=A E_{I V}^{t}\left(y^{t}, x^{t}, w^{t}\right) / A E_{I V}^{t+1}\left(y^{t+1}, x^{t+1}, w^{t+1}\right)$. If the allocative efficiency $A E_{I V}^{t}\left(y^{t}, x^{t}, w^{t}\right)=1$, it implies that the cost efficiency is identical the technical efficiency.

The fourth component of the Cost Malmquist decomposition $\Delta \mathrm{PE}$ is the price effect change, i.e.,

$$
\Delta P E==\left[\frac{\frac{C_{V}^{t+1}\left(y^{t}, w^{t+1}\right) \times D_{I V}^{t+1}\left(y^{t}, x^{t}\right)}{w^{t+1} x^{t+1}}}{\frac{C_{V}^{t}\left(y^{t}, w^{t}\right) \times D_{I V}^{t}\left(y^{t}, x^{t}\right)}{w^{t} x^{t}}} \times \frac{\frac{C_{V}^{t+1}\left(y^{t+1}, w^{t+1}\right) \times D_{I V}^{t+1}\left(y^{t+1}, x^{t+1}\right)}{w^{t+1} x^{t+1}}}{\frac{C_{V}^{t}\left(y^{t+1}, w^{t}\right) \times D_{I V}^{t}\left(y^{t+1}, x^{t+1}\right)}{w^{t} x^{t+1}}}\right]^{1 / 2}
$$

The first term insider the brace measures the impact of relative input price changes from $w^{t}$ to $w^{t+1}$ on the shift of minimum cost frontiers in producing $\left(y^{t}, x^{t}\right)$, while the second term measures the shift in producing $\left(y^{t+1}, x^{t+1}\right)$. The input effect change $\Delta \mathrm{PE}$ is then defined as the geometric mean of the terms.

The fifth component of the Cost Malmquist decomposition $\Delta$ CSE represents the cost scale efficiency change, i.e.,

$$
\Delta C S E=\left[\frac{\frac{C_{V}^{t+1}\left(y^{t+1}, w^{t+1}\right)}{C_{C}^{t+1}\left(y^{t+1}, w^{t+1}\right)}}{\frac{C_{V}^{t+1}\left(y^{t}, w^{t+1}\right)}{C_{C}^{t+1}\left(y^{t}, w^{t+1}\right)}} \times \frac{\frac{C_{V}^{t+1}\left(y^{t+1}, w^{t}\right)}{C_{C}^{t+1}\left(y^{t+1}, w^{t}\right)}}{\frac{C_{V}^{t}\left(y^{t}, w^{t}\right)}{C_{C}^{t}\left(y^{t}, w^{t}\right)}}\right]^{1 / 2}
$$

Each term of the ratio, for example, $\Delta C S E^{t}\left(y^{t}, w^{t}\right)=\frac{C_{V}^{t}\left(y^{t}, w^{t}\right)}{C_{C}^{t}\left(y^{t}, w^{t}\right)}$ measures the efficiency of getting closer to optimum scale size in minimizing the cost of producing $y^{t}$ at input price $w^{t}$. Thus, the cost scale 
efficiency change, $\triangle C S E=\left[\frac{C S E^{t+1}\left(y^{t+1}, w^{t+1}\right)}{\operatorname{CSE}^{t+1}\left(y^{t}, w^{t+1}\right)} \times \frac{C S E^{t}\left(y^{t+1}, w^{t}\right)}{\operatorname{CS} E^{t}\left(y^{t}, w^{t}\right)}\right]^{1 / 2}$ is defined as the geometric mean of the cost efficiency at scale sizes $y^{t}$ and $y^{t+1}$ in $\mathrm{t}$ and $(\mathrm{t}+1)$ periods.

Thus, overall the decomposition of the Cost Malmquist productivity index is as follows:

$\mathrm{CM}=$ pure technical efficiency change $(\Delta \mathrm{PTE}) \times$ technical efficiency change $(\Delta \mathrm{T})$

$\times$ allocative efficiency change $(\Delta \mathrm{AE}) \times$ price effect change $(\triangle \mathrm{PE})$

$\times$ cost scale efficiency change $(\triangle \mathrm{CSE})$

Values of the above five components, $\triangle \mathrm{PTE}, \Delta \mathrm{T}, \triangle \mathrm{AE}, \triangle \mathrm{PE}$ and $\triangle \mathrm{CSE}$, of greater than unity suggest deterioration, while values of less than unity suggest the improvement.

To compute and decompose the Cost Malmquist productivity index CM requires the computation of the minimum cost function under both VRS and CRS technologies, $C_{V}^{t}\left(y^{t}, w^{t}\right)$ and $C_{C}^{t}\left(y^{t}, w^{t}\right)$. For the kth DMU (i.e. sample bank) $C_{V}^{t}\left(y^{t}, w^{t}\right)$ is computed from the following linear programming problems:

$$
\begin{array}{ll}
\underset{\mathrm{x}, \lambda}{\operatorname{Min}} \quad \mathrm{w}_{\mathrm{kn}}^{\mathrm{t}} \mathrm{x}_{\mathrm{n}}=\mathrm{C}_{\mathrm{V}}^{\mathrm{t}}\left(\mathrm{y}^{\mathrm{t}}, \mathrm{w}^{\mathrm{t}}\right) \\
\\
\quad \sum_{\mathrm{j}=1}^{\mathrm{J}} \lambda_{\mathrm{j}} \mathrm{y}_{\mathrm{jm}}^{\mathrm{t}} \geq \mathrm{y}_{\mathrm{km}}^{\mathrm{t}}, \mathrm{m}=1,2, \ldots, \mathrm{M}
\end{array}
$$

subject to

$$
\begin{array}{ll}
\sum_{j=1}^{J} \lambda_{j} x_{j n}^{t} \leq x_{k n}, \quad n=1,2, \ldots, N & \\
\sum_{j=1}^{J} \lambda_{j}=1, & \lambda j \geq 0, x n \geq 0 .
\end{array}
$$

For the minimum cost function $C_{C}^{t}\left(y^{t}, w^{t}\right)$ under the constant returns to scale technology, it can be calculated by relaxing the constraint $\sum_{j=1}^{\mathrm{J}} \lambda_{\mathrm{j}}=1$ from (11). As for the mixed-period cost function $C_{V}^{t}\left(y^{t+1}, w^{t+1}\right)$, it can be similarly computed as follows:

$$
\begin{aligned}
& \operatorname{Min}_{\mathrm{x}, \lambda} \quad \mathrm{w}_{\mathrm{kn}}^{\mathrm{t}} \mathrm{x}_{\mathrm{n}}=\mathrm{C}_{\mathrm{V}}^{\mathrm{t}}\left(\mathrm{y}^{\mathrm{t}+1}, \mathrm{w}^{\mathrm{t}}\right) \\
& \sum_{\mathrm{j}=1}^{\mathrm{J}} \lambda_{\mathrm{j}} \mathrm{y}_{\mathrm{jm}}^{\mathrm{t}} \geq \mathrm{y}_{\mathrm{km}}^{\mathrm{t}+1} \quad \mathrm{~m}=1,2, \ldots, \mathrm{M}
\end{aligned}
$$

subject to

$$
\sum_{j=1}^{J} \lambda_{j} x_{j n}^{t} \leq x_{k n}, n=1,2, \ldots, N
$$




$$
\sum_{j=1}^{J} \lambda_{j}=1, \lambda j \geq 0, x n \geq 0 .
$$

Other cost functions, $C_{V}^{t+1}\left(y^{t+1}, w^{t+1}\right), \quad C_{V}^{t+1}\left(y^{t}, w^{t+1}\right), \quad C_{C}^{t+1}\left(y^{t+1}, w^{t+1}\right)$, and $C_{C}^{t+1}\left(y^{t}, w^{t+1}\right)$ are similarly obtained with and without the constraint $\sum_{j=1}^{\mathrm{J}} \lambda_{\mathrm{j}}=1$.

\section{Empirical Results}

This study uses a balanced panel data of 25 listed Taiwanese banks from 2010 to 2015. The data are collected from the TEJ database, Financial Statistics Monthly which is published by the Central Bank of Taiwan. All the nominal variables have been deflated by the annual consumer price index of Taiwan with the base year being 2010. The study adopts intermediation approach to select input and output variables. In addition to total loans $\left(\mathrm{Y}_{1}\right)$ and investments $\left(\mathrm{Y}_{2}\right)$, non-interest revenues $\left(\mathrm{Y}_{3}\right)$ was taken as an output variable, to account for the increasing proportion of fee income in bank revenue. Input variables include labor input $\left(\mathrm{X}_{1}\right)$, borrowed funds $\left(\mathrm{X}_{2}\right)$, and physical capital $\left(\mathrm{X}_{3}\right)$. The input price variables include labor price $\left(\mathrm{W}_{1}\right.$, Personnel expenses / labor input), funds price $\left[\mathrm{W}_{2}\right.$, (Deposit and loan interest expenditure) / borrowed funds] and Capital price [ $\mathrm{W}_{3}$, (Business and management expenses labor cost) / physical capital)].

All of the sample banks are commercial banks, therefore the banking activities are very much in line with each other. However, there are considerable variations in bank size. Moreover, the use of output growth to assert the increase of productivity faced the potential criticism that the increase of some DMU outputs were mainly from the accumulation and increase of factors and less from the technology advancement and efficiency improvement [8]. Therefore, the introduction and decomposition of CM are essential. Table 1 summarizes the descriptive statistics of all 25 sample banks over the observed periods.

Table 1. Descriptive Statistics by Taiwan Bank Industries for a Time Period 2010-2015

\begin{tabular}{|c|c|c|c|c|c|c|c|c|c|c|}
\hline & & Y1 & Y2 & Y3 & $\mathrm{X} 1$ & $\mathrm{X} 2$ & X3 & P1 & P2 & P3 \\
\hline \multirow{5}{*}{$\begin{array}{l}\text { Full } \\
\text { period }\end{array}$} & Mean & 769000000 & 270000000 & 3896193 & 4671 & 1020000000 & 16138410 & 6502 & 8569942 & 11032377 \\
\hline & Median & 636000000 & 224000000 & 2593204 & 4801 & 892000000 & 9295694 & 6024 & 6881394 & 10713935 \\
\hline & Maximum & 2410000000 & 1450000000 & 27361743 & 10708 & 3850000000 & 97864904 & 19855 & 36453834 & 38540275 \\
\hline & Minimum & 70217208 & 2583171 & 348633 & 865 & 108000000 & 861880 & 800 & 914619 & 1427578 \\
\hline & Std. Dev. & 601000000 & 259000000 & 4051283 & 2603 & 813000000 & 19319379 & 4508 & 7175679 & 7570297 \\
\hline \multirow[t]{5}{*}{2010} & Mean & 673000000 & 232000000 & 3435750 & 4486 & 896000000 & 14792504 & 5758 & 6103653 & 9706874 \\
\hline & edian & 538000000 & 161000000 & 2656325 & 4583 & 733000000 & 8718774 & 5985 & 4926725 & 9636106 \\
\hline & Maximum & 2090000000 & 1090000000 & 16442126 & 9538 & 3200000000 & 76596999 & 15578 & 26086235 & 28823676 \\
\hline & Minimum & 70217208 & 2583171 & 386382 & 914 & 108000000 & 2160859 & 873 & 914619 & 1492594 \\
\hline & Std. Dev. & 556000000 & 250000000 & 3333126 & 2523 & 750000000 & 16219995 & 4106 & 5653503 & 6650750 \\
\hline \multirow[t]{5}{*}{2011} & Mean & 724000000 & 233000000 & 3287511 & 4598 & 940000000 & 15831208 & 6018 & 7761437 & 10206808 \\
\hline & Median & 608000000 & 204000000 & 2439679 & 4986 & 800000000 & 9377488 & 5651 & 6886685 & 10521913 \\
\hline & Maximum & 2170000000 & 1030000000 & 15794691 & 9881 & 3230000000 & 97864904 & 15732 & 30577630 & 29498252 \\
\hline & & 82517301 & 15814755 & 348633 & 939 & 120000000 & 1412342 & 835 & 1160701 & 1438823 \\
\hline & Std. Dev. & 591000000 & 233000000 & 3241900 & 2548 & 762000000 & 20017181 & 4176 & 6662267 & 6883917 \\
\hline \multirow[t]{5}{*}{2012} & Mean & 750000000 & 247000000 & 3405285 & 4614 & 974000000 & 16121313 & 6300 & 8744876 & 10530358 \\
\hline & Median & 667000000 & 203000000 & 2497411 & 4892 & 880000000 & 9213899 & 5719 & 8438783 & 10544151 \\
\hline & Maximum & 2200000000 & 1050000000 & 17566381 & 9824 & 3310000000 & 97253348 & 16732 & 32987442 & 30847877 \\
\hline & Minimum & 86464057 & 27350212 & 348964 & 926 & 135000000 & 954086 & 867 & 1217974 & 1457642 \\
\hline & Std. Dev. & 594000000 & 234000000 & 3545365 & 2571 & 784000000 & 20196780 & 4319 & 7227135 & 7112945 \\
\hline \multirow[t]{3}{*}{2013} & Mean & 784000000 & 267000000 & 3875641 & 4686 & 1030000000 & 16236657 & 6690 & 8732611 & 11056539 \\
\hline & Median & 713000000 & 235000000 & 2572165 & 4784 & 914000000 & 10742005 & 6359 & 8551868 & 10737842 \\
\hline & Maximum & 2260000000 & 1120000000 & 19498565 & 10126 & 3430000000 & 97497978 & 18558 & 33364505 & 32542792 \\
\hline
\end{tabular}




\begin{tabular}{lllllllllll}
\hline \hline \multirow{2}{*}{2014} & Minimum & 100000000 & 25916773 & 379409 & 865 & 143000000 & 927198 & 843 & 1223033 & 1427578 \\
& Std. Dev. & 616000000 & 247000000 & 3904685 & 2693 & 827000000 & 20121041 & 4726 & 7175967 & 7613393 \\
& Mean & 825000000 & 293000000 & 4412072 & 4758 & 1100000000 & 16688947 & 7035 & 10027215 & 12008681 \\
& Median & 774000000 & 257000000 & 2537652 & 4818 & 1050000000 & 10625187 & 6964 & 10074023 & 11206606 \\
& Maximum & 2320000000 & 1190000000 & 21603872 & 10248 & 3590000000 & 97103753 & 19855 & 36453834 & 36425648 \\
& Minimum & 101000000 & 34038999 & 415437 & 878 & 143000000 & 962966 & 907 & 1379061 & 1593677 \\
& Std. Dev. & 633000000 & 266000000 & 4415854 & 2727 & 865000000 & 20399091 & 4922 & 8123481 & 8371182 \\
& Mean & 858000000 & 347000000 & 4960897 & 4886 & 1180000000 & 17159830 & 7209 & 10049864 & 12685001 \\
& Median & 847000000 & 257000000 & 3161546 & 4951 & 1130000000 & 9208471 & 7059 & 10385512 & 11390118 \\
& Maximum & 2410000000 & 1450000000 & 27361743 & 10708 & 3850000000 & 96728064 & 19814 & 36352682 & 38540275 \\
& Minimum & 126000000 & 55072226 & 451365 & 894 & 182000000 & 861880 & 800 & 1429607 & 1581235 \\
& Std. Dev. & 656000000 & 322000000 & 5535779 & 2793 & 925000000 & 20521340 & 4996 & 7876207 & 8882536 \\
\hline \hline
\end{tabular}

Note: The units of $Y_{1}, Y_{2}, Y_{3}, X_{2}$ and $X_{3}$ are in millions of USD. And the unit of $X_{1}$ is in person.

Table 2 summarizes results of the CM productivity indexes and component values for the entire sample banks in Taiwan from 2010 to 2015 . CM is decomposed into $\triangle \mathrm{PTE}, \Delta \mathrm{T}, \triangle \mathrm{AE}, \Delta \mathrm{PE}$, and $\Delta \mathrm{CSE}$. The results were computed using the models presented in Section 3. $\triangle \mathrm{CSE}$ is 1.0001 in table 2 that indicates the VRS exists in Taiwan Banking industry for the observation period. Departing from traditional approach, a value of index greater than one indicates deterioration, while a value of index less than one indicates an improvement. In the entire observation period, $\Delta \mathrm{PE}$ is improving, $\triangle \mathrm{PTE}$ remains constent, $\Delta \mathrm{T}, \Delta \mathrm{AE}$ and $\triangle \mathrm{CSE}$ are slightly decreasing. It indicates that $0.18 \% \mathrm{CM}$ index loss is significantly caused by $\triangle \mathrm{T}, \Delta \mathrm{AE}$ and $\triangle \mathrm{CSE}$. Our empirical results show that allocative efficiency change improve by $0.6 \%$ which indicate that $\triangle T, \triangle A E$ and $\triangle C S E$ are important factors contributing to the productivity loss of sample banks over the full observed period. This evidence further reconfirms that the CM outperform traditional IM approach in the sense that CM captures more insight managerial information on the productivity change.

The colum 2 of Table 2 indicates CM index are slightly grater than 1, which reveals that each of the subperiods 2010 to 2014 sample banks encoutering productivity loss. However the sources that productivity decrease may come from many various resouces. In comparision to the other observed time period, the 2014-2015 period, $\mathrm{CM}$ has the most singnificant decrease, $0.47 \% . \Delta \mathrm{T}$ is 1.0021 indicating a $0.21 \%$ decrease in technology, is the major source of change. While the other components, $\triangle \mathrm{PTE}, \Delta \mathrm{AE}, \triangle \mathrm{PE}$, $\Delta \mathrm{CSE}$ are improving.

Table 2. CM Index and Component Values of Taiwan Bank Industries for a Time Period 2010-2015

\begin{tabular}{ccccccc}
\hline \hline Year & $C M$ & $\Delta P T E$ & $\Delta T$ & $\Delta A E$ & $\Delta P E$ & $\Delta C S E$ \\
\cline { 2 - 6 } Base Year & $(\mathrm{B})$ & $(\mathrm{C})$ & $(\mathrm{D})$ & $(\mathrm{F})$ & $(\mathrm{G})$ & $(\mathrm{H})$ \\
$2010-2011$ & 1.0000 & 1.0000 & 1.0000 & 1.0000 & 1.0000 & 1.0000 \\
$2011-2012$ & 1.0025 & 1.0001 & 1.0018 & 1.0016 & 0.9944 & 0.9998 \\
$2012-2013$ & 1.0007 & 1.0004 & 1.0030 & 1.0013 & 0.9937 & 1.0011 \\
$2013-2014$ & 1.0018 & 0.9998 & 1.0039 & 1.0002 & 0.9942 & 1.0004 \\
$2014-2015$ & 1.0047 & 0.9999 & 1.0021 & 0.9987 & 0.9958 & 0.9990 \\
Full period & 1.0018 & 1.0000 & 1.0022 & 1.0006 & 0.9954 & 1.0001 \\
\hline \hline
\end{tabular}

$\mathrm{CM}=\Delta \mathrm{PTE} \times \Delta \mathrm{T} \times \Delta \mathrm{AE} \times \Delta \mathrm{PE} \times \Delta \mathrm{CSE}$

\section{Conclusion}

The development of financial technology has fostered a wave of revolutionary change in financial service industry worldwide. In fact, the Fintech start-ups provide divinity of banking services in a trustable and 
much efficient way which are taking out the market share and changing the landscape of financial incumbent. The evaluation of productivity change during the Fintech era has become a very important issue. On the other hand, the CM approach has evolved as a more preferred approach to the measurement of firm productivity. The objective of this study is to investigate the effect of Fintech on the productivity in the Taiwan banking industry. To investigate such potential effect, the study use the CM, to estimate the 25 listed sample banks over the period from 2010 to 2015. The empirical result suggests the observed period, $2014-2015$, the $\Delta \mathrm{PTE}, \Delta \mathrm{AE}, \Delta \mathrm{PE}$, and $\Delta \mathrm{CSE}$ are improving by $0.01 \%, 0.13 \%, 0.42 \%$, and $0.10 \%$ respectively. Consistent with the objective of Fintech development, which attends to provide banking service in a more effcient operation and less cost. Although the level of technology improvement requires longer time horizon, but the above captioned index reveals that the adoptions of financial technology proposed by bank regulators carry the positive effect on the overall competiveness of the banking industry in Taiwan.

\section{References}

[1] Maniadakis, N., \& Thanassoulis, E. (2004). A cost malmquist productivity index. European Journal of Operational Research, 154, 396-409.

[2] Yang, Y. L., \& Huang, C. J. (2009). Estimating the malmquist productivity index in the Taiwanese banking industry: A production and cost approach. Taiwan Economic Review, 37(4), 353-378.

[3] Yang, Y. L., Sheng, T. C., \& Huangm M. H. (2010). Estimating the cost malmquist productivity index in the Taiwan biotech and biopharmaceutical industry. Taiwan Journal of Applied Economics, 59-85.

[4] Shephard, R.W. (1970). Theory of Cost and Production Functions. USA: Princeton University Press.

[5] Färe, R. (1988). Fundamentals of production theory. Lecture Notes in Economics and Mathematical Systems, 311.

[6] Färe, R., Grosskopf, S., Norris, M., \& Zhang, Z. (1994). Productivity growth, technical Progress and efficiency change in industrialized countries. American Economics Review, 84, 66-83.

[7] Farrell, M. J. (1957). The measurement of productive efficiency. Journal of the Royal Statistical Society, 120, 253-281.

[8] Kumbhakar, S. C., \& Wang, H. J. (2005). Estimation of growth convergence using a stochastic production frontier approach. Economics Letters, 88, 300-305.

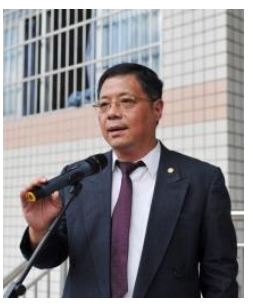

Yung-Lieh Yang was born on Aug. 11, 1965 at Changhua in Taiwan. He earned his Ph.D. in economics from Soochow University in 1999. He was professor and dean of College of Finance and Economics, and College of Management (2010-2017). He is vice president of Ling Tung University, Taiwan (2015-2017). His major research interest is on efficiency and productivity. He has published 12 refereed journal papers, for example, Empirical Economics (2017), Contemporary Economic Policy (2011). He is a member of the Taiwan Efficiency and Productivity Association (TEPA).

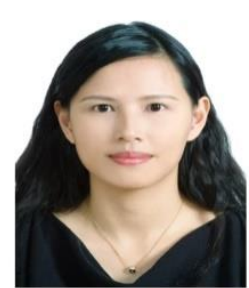

Hsiu-Wen Hsueh was born in Changhua, Taiwan on Nov. 19, 1978. She is a doctorial student in the Department of Industrial Education and Technology of NCUE from Sep., 2015. She is administrative assistant in B. A. Dept. of NCUE since 2002. She has earned the outstanding administrative staff award of NCUE in 2013. She has published a paper on refereed journal, Technics technologies education management (Vol.9, No 2, 2014). 


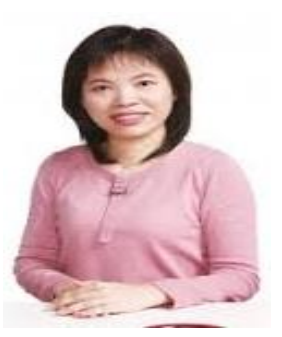

Tsui-Yueh Cho was born in Taichung city, R.O.C. and got a financial doctorate in National Changhua University of Education. She is an associate professor in the Department of Insurance and Finance of National Taichung University of Science and Technology.Her research field was focus on financial management, efficiency and productivity analysis. She has been published articles in Taiwan Journal of Applied Economics, Educational Policy Forum and Journal of Valuation.

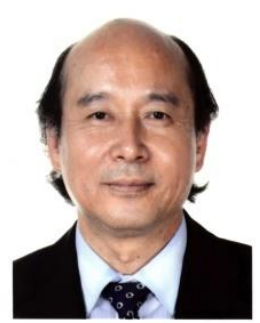

Ming-Hsiang Huang was born in Taichung, Taiwan in Dec. 20, 1953. He earned his DBA in Finance from Mississippi State University in 1999. He is a professor of Finance in B. A. Dept., NCUE. He was Chairperson of B.A. Dept., and Dean of Academic Affairs, NCUE. He is a member of TEPA, and Beta Gama Sigma. His research interest is in financial institution management. He has published papers on refereed journals, for example, Review of Financial Economics, Academia Economic Papers, Review of Security and Futures Markets, Physica A, Journal of Information and Optimization Sciences.

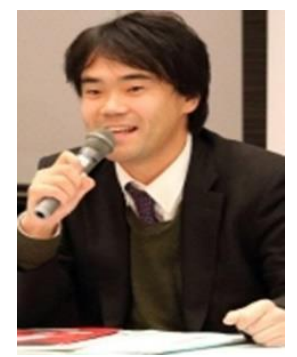

Yausuyuki Kishi was born on Sep. 30, 1979 in Tokyo, Japan. He is an associate professor of management and sociology of Niigata University, Japan, with research interests in globalization, SMEs, human resource management and cross-cultural studies. He received his $\mathrm{PhD}$. in International Sociology from Waseda University. He served as an Honorary Research Associate at the University of Hong Kong. He is a member of Academy of International Business, Academy of Japanese Business Studies and many of International Academic Associations. His papers have published in many refereed journals, for example, The Journal of Economics (2016), Management and Business Administration (2014), Asian Business \& Management (2013), The Academic Association for Organizational Science (2013). 